\title{
Cyclooxygenase-2 knockdown by RNA interference in colon cancer
}

\author{
GEORGE S. CHARAMES ${ }^{1-3}$ and BHARATI BAPAT ${ }^{1-3}$ \\ ${ }^{1}$ Department of Pathology and Laboratory Medicine, ${ }^{2}$ Samuel Lunenfeld Research Institute, Mount Sinai Hospital; \\ ${ }^{3}$ Department of Laboratory Medicine and Pathobiology, Faculty of Medicine, University of Toronto, Toronto, Canada
}

Received August 10, 2005; Accepted September 22, 2005

\begin{abstract}
Overexpression of cyclooxygenase-2 (COX-2) is observed early in colon cancer. Treatments with COX-2specific NSAIDs have been shown to reduce polyp size and polyp number in FAP patients with a predisposition to colorectal adenoma and cancer. However, the use of COX-2specific NSAIDs in colon cancer patients has recently revealed increased cardiovascular risks. These harmful side effects may be the result of COX-dependent and/or COX-independent mechanisms. RNA interference (RNAi) is a method of posttranscriptional gene silencing intrinsic to cells. This study employed RNAi to specifically knockdown endogenous COX-2 expression in the HT-29 colon cancer cell line, and to observe the apoptotic response as well as 15-hydroxyprostaglandin dehydrogenase (15-PGDH) expression levels. Following treatment with a COX-2 siRNA, we demonstrated a significant knockdown at the protein level of $57 \%$ as compared to a non-silencing siRNA control. Protein results were corroborated by concurrent decrease in COX-2 mRNA levels following the same treatment regimen. Despite previous studies using NSAID treatment to implicate COX-2 involvement in apoptosis, we did not observe any alteration in Bcl-2 expression and Caspase-3 activation following COX-2 knockdown in these cells. 15-PGDH, a physiological antagonist of COX-2 in its catabolism of $\mathrm{PGE}_{2}$, showed a modest but significant induction in response to $\mathrm{COX}-2$ knockdown. The precise role of COX-2 in apoptosis and $\mathrm{PGE}_{2}$ regulation remains unclear; however, having shown that down-regulation of endogenous levels of COX-2 can be achieved in colon cancer by RNAi, this strategy should prove to be a valuable tool in revealing the specific function of COX-2 in tumourigenesis.
\end{abstract}

Correspondence to: Dr Bharati Bapat, Samuel Lunenfeld Research Institute, Mount Sinai Hospital, 600 University Ave, Room 992B, Toronto, ON, M5G 1X5, Canada

E-mail: bapat@mshri.on.ca

Key words: COX-2, RNAi, colon cancer, 15-PGDH

\section{Introduction}

Cyclooxygenase (COX) catalyzes a key step in the formation of prostaglandins (PGs) $(1,2)$. COX enzymes regulate the synthesis of prostaglandins and thromboxanes from free arachidonic acid, a 20-carbon polyunsaturated fatty acid liberated from membrane phospholipids by $\mathrm{PLA}_{2}$. PGs have important functions in almost every organ system and regulate such diverse physiological processes as immunity, reproduction, maintenance of vascular integrity and tone, nerve growth and development, and bone metabolism. PGs are synthesized in a broad range of tissue types and act as autocrine or paracrine mediators to signal changes within the immediate environment.

Two isoforms of the COX enzyme exist, COX-1 and COX-2. COX-1 is involved in the maintenance of tissue homeostasis, constitutively expressed with near constant levels and activity in many tissues, including the mucosa of the gastrointestinal tract where it is believed to protect against gastric damage. COX-2 is minimally expressed in most tissues, but is capable of induction at sites of inflammation as evidenced by increased mRNA, protein and enzymatic activity of COX-2 as high as 10 -fold or more, which then promptly returns to the basal level. Exceptions include components of the central nervous system, the kidney and the seminal vesicles, which contain constitutively high levels of COX-2.

COX-2 is overexpressed in colon, breast, pancreatic, lung, and stomach cancers (3-13). Genetic and pharmacological studies suggest that COX-2 induction is an early step in colorectal tumourigenesis, as seen by COX-2 expression in the aberrant crypt foci, one of the earliest detectable premalignant lesions in colorectal tumourigenesis (14). COX-2 has also been shown to be overexpressed in $40-50 \%$ of premalignant adenomas and $80-90 \%$ of human colorectal carcinomas (15). Perhaps the most striking evidence implicating COX-2 in colon carcinogenesis is the finding that a null mutation for COX-2 markedly reduced the number and size of intestinal tumours in the $\mathrm{APC}^{\Delta 716}$ knockout mice, a murine model of familial adenomatous polyposis (FAP) (16). This result suggests that COX-2 is a rate-limiting step in the formation of intestinal polyps. In two different APC knockout mouse models, $\mathrm{APC}^{+/-\Delta 716}$ and min mice, adenomas at early stages showed loss of heterozygosity of the normal APC allele concurrent with COX-2 overexpression $(16,17)$. Previous studies have shown that induction of full-length APC in a colon cancer cell line (HT-29) that carries a mutant APC 
down-regulates COX-2 mRNA and protein expression (18). This suggests that COX-2 is a downstream target of the Wntsignaling pathway; and further implies that COX-2 may be involved in the promotion of colorectal adenomas, as is the case with several downstream targets of Wnt signaling $(19,20)$.

In colon cancer, COX-2 catalyzes the oxidation of arachidonic acid, which produces prostaglandins and highly reactive by-products that may accelerate the carcinogenesis process. However, the precise mechanism by which COX-2 expression and catalysis results in tumour formation is not understood. It is possible that COX-2 catalysis removes a protective agent and/or generates an oncogenic agent or agents. High concentrations of free arachidonic acid can promote apoptosis, independent of prostaglandin formation (21). It is possible that the increased levels of COX-2 serve to lower the intracellular level of free arachidonic acid and thereby prevent apoptosis. Thus, COX-2 catalysis may be simply a process that depletes an apoptotic signal. Alternatively, products formed by the enzymatic action of COX-2, presumably one of the prostaglandins, alter cell growth, apoptosis, angiogenesis or other steps involved in tumourigenesis (22-24). COX-1 and COX-2 have been shown to cooperate to induce angiogenesis and $\mathrm{PGE}_{2}$ inhibits programmed cell death by inducing expression of the $\mathrm{Bcl}-2$ protooncogene (24). $\mathrm{PGE}_{2}$ and other prostaglandins often elevate intracellular cyclic AMP concentrations which can suppress apoptosis.

A physiological antagonist of COX-2, 15-hydroxyprostaglandin dehydrogenase (15-PGDH), has recently emerged as one of the key players down-regulated in colon cancer $(25,26)$. In normal tissue, $\mathrm{PGE}_{2}$ levels are regulated via a balance between its synthesis, through the cyclooxygenase pathway, and its degradation via 15-PGDH (27). This balance is shown to be shifted, marked by a loss of 15-PGDH expression in colorectal, breast, and lung carcinomas (25). These observations suggest a putative tumour suppressive role for 15-PGDH. Whether perturbation of COX-2 expression levels have any bearing on 15-PGDH expression in colon tumours is not known and is examined in this study.

In previous studies of azoxymethane-induced colon carcinogenesis in rats, treatment with a selective COX-2 inhibitor (NS-398) has been shown to reduce tumour size and multiplicity $(28,29)$. The clinical relevance of these findings was shown in patients with germline mutations in the APC gene and the autosomal dominant inherited syndrome of FAP, where treatment with the NSAID, sulindac, or the selective COX-2 inhibitor, celecoxib, has been shown to effectively regress existing colorectal adenomas compared to the placebo $(30,31)$. Furthermore, NSAID treatments aimed at inhibiting COX-2 have proven chemopreventive, reducing both polyp number and polyp burden following clinical trials in colon cancer patients (31). The specific chemopreventive mechanisms of NSAIDs, including the so-called 'selective COX-2 inhibitors' (known as coxibs), remain unknown, although several studies have demonstrated that coxibs likely mediate their effects through both COX-dependent and -independent pathways (32). Despite these benefits, emerging data has shown that the use of coxibs is associated with harmful side effects. Whether some of these side effects occur due to COX-2-mediated or -independent mechanisms is not yet known. These observations underscore the importance of specifically targeting and inhibiting COX-2 in colon cancer in order to examine the true role of COX-2 in tumour development. This study explored the possibility of COX-2 knockdown in colon cancer though a novel approach, RNA interference.

RNA interference (RNAi) is a sequence-specific posttranslational gene silencing mechanism which is triggered by double-stranded RNA and causes degradation of mRNAs homologous in sequence to the dsRNA (33-35). Using RNAi to target genes expressing potentially oncogenic proteins similar to COX-2 has provided excellent proof of principle for RNAi as an anti-cancer therapeutic agent. Successful RNAi treatment will provide an effective strategy to decipher the role of COX-2 in carcinogenesis.

In this study, we have utilized RNAi to specifically knockdown endogenous levels of COX-2 in a colon cancer cell line. This novel approach provides a suitable model system to examine the specific role of COX-2 and its relationship to biological and tumourigenic processes, such as apoptosis in colon cancer.

\section{Materials and methods}

Cell culture. The HT-29, RKO, SW480, and HCT 116 colon cancer cell lines and the MDA-MB-231 breast cancer cell line were obtained from American Type Culture Collection (ATCC). The SW480 cell line was maintained in Leibovitz's L-15 medium with $2 \mathrm{mM}$ L-glutamine containing $10 \%$ fetal bovine serum (FBS) at $37^{\circ} \mathrm{C}$ in an atmosphere without $\mathrm{CO}_{2}$. All other cell lines were cultured in Dulbecco's modified Eagle's medium (DMEM) containing $10 \% \mathrm{FBS}$ at $37^{\circ} \mathrm{C}$ in an atmosphere containing $5 \% \mathrm{CO}_{2}$.

Transfections. HT-29 cells were plated in 6-cm dishes and grown to approximately $50 \%$ confluency. After $24 \mathrm{~h}$, the cells were transfected with siRNA in Lipofectamine 2000 (Invitrogen) reagent according to the manufacturer's protocol. Briefly, for each dish, $20 \mu 1$ of Lipofectamine 2000 reagent was incubated with $500 \mu 1$ of serum-free medium for $5 \mathrm{~min}$. Subsequently, a mixture of $20 \mu 1$ of the respective siRNA in annealing buffer stock and $500 \mu 1$ medium was added. After incubation for $20 \mathrm{~min}$ at room temperature, the combined mixture was dropwise added to each well, resulting in an siRNA concentration of $10 \mathrm{nM}$. The cells were incubated for a further $72 \mathrm{~h}$ before use in the various assays. The COX-2 siRNA was chemically synthesized (Qiagen) according to the published sequence, 5'-AAACTGCTCAACACCGGAATTT TT-3', nucleotides 291-313 of the cDNA sequence (36). A non-specific control (non-silencing) siRNA against the target sequence, 5'-AATTCTCCGAACGTGTCACGT-3', was also chemically synthesized by Qiagen. The GAPDH siRNA was a generous gift from Dr G. Hannigan (Hospital for Sick Children, Toronto, Canada).

Western blot analysis. HT-29 cells were harvested in $200 \mu 1$ of $50 \mathrm{mM}$ Tris $\mathrm{Hcl}(\mathrm{pH} 7.4)$ containing $1 \mathrm{mM}$ EDTA, $1 \%$ Triton, and $150 \mathrm{mM} \mathrm{NaCl}$. Protein concentration was calculated using the BCA Protein Assay kit (Pierce) and $40 \mu \mathrm{g}$ protein/ sample was loaded on a $10 \%$ polyacrylamide gel. Proteins were blotted onto Hybond-P PVDF membranes (Amersham), 
Table I. Primer and probe sequences for quantitative real-time PCR analysis.

\begin{tabular}{lcc}
\hline Gene & Type & $\begin{array}{c}\text { Sequence } \\
\left(5^{\prime} \text { to } 3^{\prime}\right)\end{array}$ \\
\hline COX-2 & Forward primer & GCTGGAACATGGAATTACCCA \\
COX-2 & Reverse primer & CTTTCTGTACTGCGGGTGGAA \\
COX-2 & Probe & Forward primer \\
$15-P G D H$ & Reverse primer & TGCTTCAAAGCATGGCATAG \\
$15-P G D H$ & Forward primer & AACAAAGCCTGGACAAATGG \\
ß-actin & Reverse primer & ATCATGTTTGAGACCTTCAA \\
\hline
\end{tabular}

activated with methanol. Following a 4-h protein transfer, the blots were washed in TBS-T, Tris-buffered saline containing $1 \%$ Tween-20 (Bio-Rad), and blocked for $1 \mathrm{~h}$ in $5 \%$ non-fat dry milk in TBS-T. Membranes were incubated overnight with a mouse monoclonal anti-COX-2 antibody (1:500 in 5\% milk, Cayman Chemical) at room temperature, with mouse monoclonal anti- $\beta$-actin antibody (1:8000 in 5\% milk, Sigma), with mouse monoclonal anti-Caspase- 3 antibody $(1: 1000$ in $5 \%$ BSA, Cell Signaling) at $4{ }^{\circ} \mathrm{C}$, or with rabbit polyclonal anti-Bcl-2 antibody (1:1000 in 5\% BSA, Cell Signaling) at $4^{\circ} \mathrm{C}$. Incubation with a horseradish-peroxidase conjugated secondary antibody (goat anti-mouse, 1:2000 in 5\% milk, Bio-Rad; or donkey anti-rabbit, 1:2000 in milk, Amersham) for $4 \mathrm{~h}$ at room temperature. Bands were visualized using the ECL plus system (Amersham). Relative COX-2 protein concentrations were determined by densitometry of the scanned radiography image with the Quantity One 1-D Analysis v.4.5.2 software (Bio-Rad). All values were normalized for loading in comparison with the appropriate $B$-actin signal.

Quantitative real-time reverse transcription-polymerase chain reaction ( $Q R T-P C R)$. Total RNA was isolated from HT-29 cells using the RNeasy Mini Kit (Qiagen) according to the manufacturer's instructions. The RNA was quantified by determining absorbance at $260 \mathrm{~nm}$. First-strand cDNA was synthesized from $5 \mu \mathrm{g}$ RNA using SuperScript III Reverse Transcriptase (Invitrogen). Real-time PCR was performed using both TaqMan [Applied Biosystems (ABI)] probe-based and SYBR Green I dye (ABI) assay chemistries, and carried out in an Applied Biosystems 7900HT fast real-time PCR system. TaqMan probe-based assay chemistry was used to quantitate $C O X-2$ mRNA, while the $15-P G D H$ mRNA and the $B$-actin housekeeping gene mRNA were quantitated using SYBR Green I dye assay chemistry; both utilized in the same 96-well plate. Samples were analyzed in duplicate (triplicate when wells were available). Real-time results were collected and analyzed (Standard Curve Method) using the Sequence Detection System (SDS) software, version 2.0 (ABI), according to the manufacturer's protocol.

TaqMan probe-based assay. A mixture of 10X buffer ( $3 \mu 1 /$ well), $10 \mathrm{mM}$ dNTPs (0.6 $\mu 1 /$ well), $25 \mathrm{mM} \mathrm{MgCl} 2$ (4.2 $\mu \mathrm{l} / \mathrm{well})$, $10 \mu \mathrm{M}$ forward primer $(0.9 \mu \mathrm{l} /$ well $), 10 \mu \mathrm{M}$ reverse primer

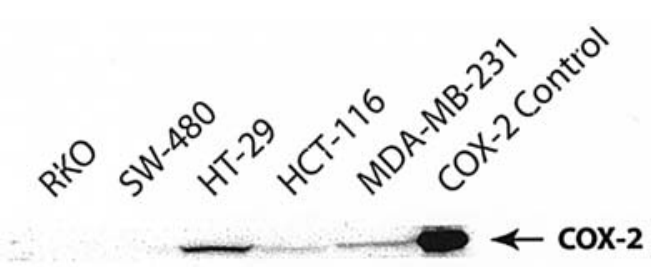

Figure 1. Western blot analysis to determine COX-2 protein expression in a panel of four colon cancer cell lines. A breast cancer cell line (MDA-MB-231) has been included as a positive control along with the positive control supplied by the manufacturer of the primary antibody. COX-2 is a $72-\mathrm{kDa}$ protein.

(0.9 $\mu \mathrm{l} /$ well), $10 \mu \mathrm{M}$ TaqMan gene-specific probe (0.9 $\mu \mathrm{l} /$ well), AmpliTaq Gold $(0.15 \mu \mathrm{l} /$ well) and DNase-free water to bring the reaction to $30 \mu \mathrm{l}$ was added to each well containing $1 \mu \mathrm{l}$ of cDNA. See Table I for primer and probe sequences.

SYBR Green I dye assay. A mixture of 2X SYBR Green (15 $\mu \mathrm{l} /$ well), $10 \mu \mathrm{M}$ forward primer $(0.6 \mu \mathrm{l} /$ well $), 10 \mu \mathrm{M}$ reverse primer $(0.6 \mu \mathrm{l} /$ well $)$ and DNase-free water to bring the reaction to $30 \mu 1$ was added to each well containing $1 \mu 1$ of cDNA. See Table I for primer sequences.

\section{Results}

In a panel of four colon cancer cell lines and one breast cancer cell line, HT-29 displayed the highest expression of endogenous COX-2 protein (Fig. 1). This was also confirmed at the mRNA level by Northern blot analysis (data not shown). Therefore, HT-29 was selected as an ideal candidate for COX-2 knockdown. COX-2 protein expression was reduced by $57 \%$ following transfection with the COX-2 siRNA (10 nM) for $72 \mathrm{~h}$ as compared to transfection with a commercially available non-silencing control (Fig. 2). Control experiments included transfection with GAPDH siRNA and showed that COX-2 expression was reduced by only $8 \%$ in these cells. The quantification of protein expression was carried out using densitometry analysis of the Western blot membranes, and values were compared against the $\beta$-actin housekeeping gene to normalize protein loading. COX-2 knockdown was further analyzed at the mRNA level by QRT-PCR. COX-2 mRNA expression was reduced by about $25 \%$ in the HT-29 colon 
A

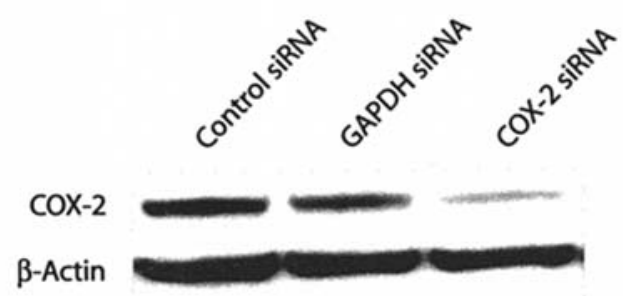

B

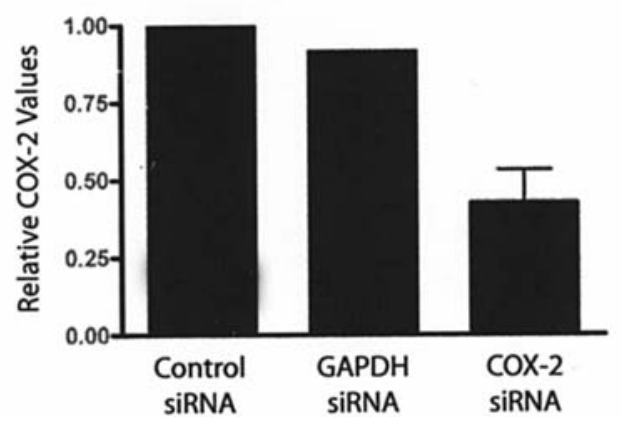

Figure 2. COX-2 protein expression knockdown in HT-29 colon cancer cells. (A), Western blot analysis of HT29 cells following COX-2 siRNA (10 nM) treatment as compared to treatment with a non-silencing control and GAPDH siRNAs $(10 \mathrm{nM})$. (B), Densitometry analysis of Western blots following COX-2 knockdown. Mean $( \pm$ SE) of four independent COX-2 iRNA and one GAPDH siRNA experiments are shown.

cancer cell line $72 \mathrm{~h}$ post-COX-2 siRNA transfection as compared to transfection with the non-silencing siRNA control (Fig. 3).

The downstream product of cyclooxygenase activity, $\mathrm{PGE}_{2}$, is shown to be involved in a number of tumourigenic processes. In normal colon tissue, 15-PGDH can regulate $\mathrm{PGE}_{2}$ levels by $\mathrm{NAD}^{+}$-dependent degradation. While $\mathrm{PGE}_{2}$ is generated by COX-2 activity, its ability to evade degradation possibly arises from loss of 15-PGDH expression, which is known to occur in colon cancer. We sought to evaluate 15PGDH expression at transcriptional levels in response to COX-2 knockdown. In these experiments, 15-PGDH mRNA expression exhibited modest induction following COX-2 knockdown after $72 \mathrm{~h}$ by QRT-PCR (Fig. 3). While this data appears promising, additional studies aimed at clearly elucidating 15-PGDH expression regulation by COX-2 are required.

To evaluate the effects of endogenous COX-2 knockdown on cell survival, we looked for evidence of apoptotic induction. Previous studies have shown that COX-2 stable transfection induces up-regulation of anti-apoptotic Bcl-2 mRNA and protein in HCT-15/COX-2 cells relative to the parental cell, implying that COX-2 acts through suppressing the mitochondrial apoptotic pathway (37). Therefore, we assessed Bcl-2 expression following COX-2 knockdown. Bcl-2 expression levels were unchanged as seen by Western blot analysis (Fig. 4). Since both mitochondrial and death receptor apoptotic pathways activate Caspase-3, we also examined the presence of the cleaved Caspase- 3 products following RNAi (38-40). We did not observe any evidence

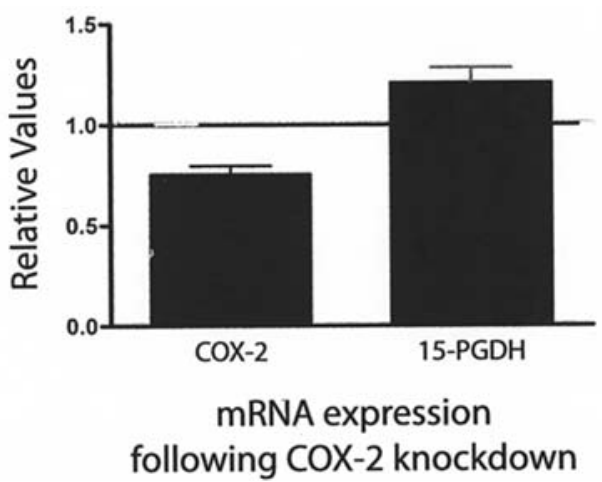

Figure 3. Real-time quantitative RT-PCR analysis following COX-2 siRNA transfection in HT29 cells relative to transfection with a non-silencing siRNA. COX-2 and 15-PGDH mRNA expression changes in response to COX-2 knockdown. COX-2 knockdown and 15-PGDH induction are significant according to a one sample t-test $(\mathrm{P}<0.0001$ and $\mathrm{P}=0.0186$, respectively) performed using GraphPad Prism 4. Data represent mean of triplicate measurements; bars, $\pm \mathrm{SE}$.

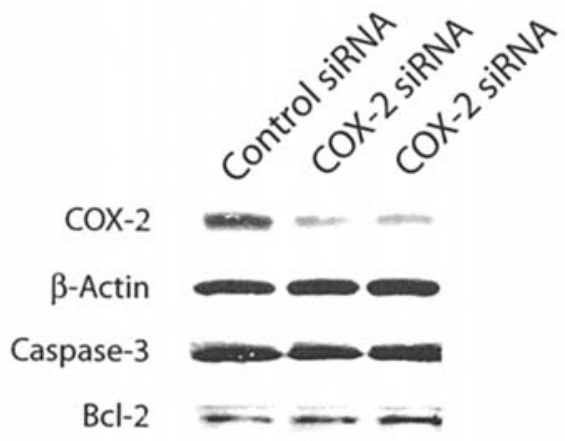

Figure 4. Bcl-2 and Caspase-3 protein expression following COX-2 knockdown in the HT-29 colon cancer cell line. Bcl-2 (28 kDa) and Caspase-3 $(35 \mathrm{kDa})$ protein expression were unaffected following COX-2 siRNA treatments (as compared to treatment with a non-silencing siRNA control) by Western blot analysis. Caspase-3 activation, marked by the generation of 19and 17-kDa cleaved products was not detected (data not shown). The COX-2 and $\beta$-actin protein molecular weights are $72-$ and $42-\mathrm{kDa}$, respectively.

of apoptosis following COX-2 knockdown in the HT-29 cell line (Fig. 4).

\section{Discussion}

In this study, we have demonstrated a significant reduction of endogenous COX-2 levels in colon cancer cells using RNA interference (RNAi) strategy. RNAi has emerged as a novel effective genetic tool for post-transcriptional gene silencing. The RNAi machinery, intrinsic to all mammalian cells, can knock down genes with great specificity and, thus, has great promise as an effective therapeutic agent. Prior to this study, RNAi-mediated knockdown of endogenous levels of COX-2 has not been reported in colorectal cancer.

Overexpression of cyclooxygenase-2 (COX-2) has been identified as a key event in early tumour development, particularly in colon cancer. Treatment with NSAIDs specifically targeting COX-2 has given promising results by reducing colonic polyp size and number (31). However, these same drugs have recently been shown to cause harmful side 
effects which put their users at risk of cardiovascular events such as myocardial infarctions and thrombotic stroke (41). Further studies of NSAID-mediated anti-tumourigenic effects have also uncovered their involvement in COX-independent pathways, which may contribute to these potentially fatal risks (42). These observations warrant developing strategies that effectively target $\mathrm{COX}-2$ regulation with a greater specificity. This study sought to avoid the pitfalls of NSAID treatment and employed RNAi to specifically knock down endogenous COX-2 in colon cancer cells.

Denkert et al (36) explored the role of COX-2-specific knockdown on G0/G1 cell-cycle arrest in ovarian carcinoma cells as compared to the COX-2-specific inhibitor, NS-398 (36). They found that the OVCAR-3 ovarian cancer cell line, although devoid of endogenous COX-2 expression, was able to express COX-2 following induction with IL-1ß. Following transfection of these ovarian cancer cells with a COX-2-specific siRNA, they were able to knock down this induced COX-2 expression. We used the same siRNA target sequence to knock down the endogenous COX-2 expression in the HT-29 colon cancer cell line.

Although the Denkert et al study was the first to demonstrate reductions of IL-1ß-induced COX-2 expression by RNAi, studies aimed at down-regulating COX-2 gene expression have been previously explored using other techniques. Tsujii and DuBois have shown that rat intestinal epithelium cells stably transfected with a COX-2 expression vector oriented in the antisense direction exhibited more than twice the amount of apoptotic cells as compared to parental cells (43). Maier et al followed a similar strategy and were able to show COX-2 reduction in Caco- 2 colon cancer cells by transfection with COX-2 cDNA in antisense orientation as compared to an empty vector control (32). Recently, Sun and Sinicrope treated HCA-7 colon cancer cells with sulindac sulfide to induce COX-2 protein expression and apoptosis (44). Treatment of these cells with COX-2 antisense oligonucleotides blocked both constitutive and sulindac sulfideinduced COX-2 protein expression. While dose-dependent induction of apoptosis by sulindac sulfide was significantly elevated in COX-2 anti-sense-treated HCA-7 cells, apoptosis was not examined following constitutive suppression.

COX-2 overexpression in colon cancer has been implicated to be involved in processes such as angiogenesis, cell proliferation, and the inhibition of apoptosis (24,45-47). Although activation of effector caspases, including caspase-3, perform proteolytic cleavage events involved in both (mitochondrial and membrane death receptor) apoptotic pathways, most anticancer drugs induce apoptosis by engaging the cytochrome$c$-dependent mitochondrial apoptotic pathway. This pathway is negatively regulated by the antiapoptotic $\mathrm{Bcl}-2$ protein through suppression of cytochrome- $c$ release. Previous studies have shown that, in the HCT-15 colon cancer cell line, induction of COX-2 expression was associated with inhibition of the mitochondrial apoptotic pathway characterized by reduced cytochrome- $c$ release, attenuated caspase- 9 and -3 activation, and up-regulation of Bcl-2. Following knockdown of endogenous COX-2 in the HT-29 colon cancer cell line, we sought to observe the apoptotic response by observing caspase-3 and Bcl-2 expression levels. We elected to assess $\mathrm{Bcl}-2$ expression in order to capture early signals in the mitochondrial apoptotic pathway. However, should COX-2 regulate either pathway without preference, caspase- 3 activation is the earliest point where both pathways feed through. We did not observe caspase- 3 activation (marked by cleavage) or $\mathrm{Bcl}-2$ reduction, which may indicate that changes at the endogenous level may not be sufficient for detection by Western blotting. Alternatively, the apoptotic events observed in studies that inhibit COX-2 by NSAIDs are due to COX-independent mechanisms, and specific knockdown of endogenous COX-2 by RNAi may circumvent the non-specific activities of coxibs. Future studies are needed to fully decipher the molecular and biological mechanisms underlying COX-2 expression in colon cancer cells.

Both non-selective COX inhibitors and COX-2-specific inhibitors have been shown to inhibit cell proliferation and induce apoptosis of colon and several cultured tumour cell lines. However, the doses of NSAIDs, found to exert these effects in vitro, have generally been well in excess of pharmacological concentrations, thereby questioning the clinical relevance of these findings. Further evidence in support of COX-independent mechanisms operating under NSAID influence include published studies showing that NSAIDs can inhibit the growth of cancer lines devoid of COX-2 expression (such as SW480 and HCT 116) as they do for those producing COX-2 (eg. HT-29 and Caco-2). In other studies, murine embryonic fibroblasts with homologous knockout of COX-1 and -2 alleles remain sensitive to the anti-proliferative and pro-apoptotic effects of NSAIDs. In this context, the absence of apoptosis inhibition following COX-2 knockdown in our study may suggest that NSAIDmediated apoptosis is regulated by COX-2-independent mechanisms or that cell death due to COX-2 knockdown occurs via mechanisms independent of apoptosis. Alternatively, it is possible that $>60 \%$ of COX-2 knockdown may be required to see its effect on apoptosis or that the effect is subtle and the cells need to be exposed to stress (eg. treatment to ionizing radiation) in order to increase the sensitivity of these apoptosis assays. Interestingly, the COX-2 knockdown achieved in ovarian cancer cells (OVCAR-3) following induction due to interleukin- $1 \beta$ treatment also did not demonstrate any effect on apoptosis.

Overexpression of COX-2 in colon cancer also yields increased local levels of $\mathrm{PGE}_{2}$. Elevated levels of the COX-2derived $\mathrm{PGE}_{2}$ are associated with resistance to programmed cell death as well as stimulation of cell migration, cell proliferation, and angiogenesis. The intracellular concentrations of available $\mathrm{PGE}_{2}$ depend on the relative rates of biosynthesis and breakdown. Recent studies have highlighted the importance of the elimination of this bioactive lipid. The biochemical activity of COX-2 related to increasing $\mathrm{PGE}_{2}$ levels has a normal physiological antagonist in 15-hydroxyprostaglandin dehydrogenase (15-PGDH), an enzyme which catalyzes the rate-limiting step of prostaglandin catabolism. While normal human and mouse colonic tissue has been found to contain high levels of 15-PGDH transcript and protein, it is nearly undetectable in colon cancers. This suggests colon cancer development may require two cooperating hits, one a dramatic up-regulation of expression of the COX-2 oncogene, and the other a dramatic down-regulation of an opposing and putative tumour suppressor gene, 15-PGDH. Recent studies have 
shown that molecular mechanisms of COX-2 induction and 15-PGDH down-regulation may operate in parallel (26). In this study, we identified a modest elevation of 15-PGDH transcript levels in response to COX-2 knockdown. This intriguing observation may suggest that, while COX-2 induces its tumourigenic processes by generating excess $\mathrm{PGE}_{2}$, it may play an active role in sustaining the $\mathrm{PGE}_{2}$ levels by downregulating 15-PGDH expression. Alternatively, $\mathrm{PGE}_{2}$ levels may influence 15-PGDH expression via some form of feedback loop mechanism. Future studies aimed at addressing such possibilities are needed.

It has been argued that, although HT-29 cells express high levels of COX-2, this expression is not translated into a metabolically active protein as identified by $\mathrm{PGE}_{2}$ output (48). Hsi et al investigated $\mathrm{PGE}_{2}$ in HT29, HCT-116, and Caco-2 colon cancer cell lines following treatment with radioactively-labeled arachidonic acid. By $\mathrm{HPLC}, \mathrm{PGE}_{2}$ production was found only in Caco-2 cells and not in HCT-116 or HT-29 cells post treatment. The authors concluded that, since exogenous introduction of labeled arachidonic acid did not metabolize into $\mathrm{PGE}_{2}$, these cells must be catalytically inactive. However, many subsequent studies have used ELISA assays to look for endogenous $\mathrm{PGE}_{2}$ production in HT-29. For example, Kakiuchi et al (49) investigated a link between COX-2 and enhanced adhesion of carcinoma cells to endothelial cells. In baseline analysis of COX-2 activity in colon cancer cell lines, including HT-29 and Caco-2, they measured $\mathrm{PGE}_{2}$ production at approximately $20 \mathrm{ng} / 10^{6}$ cells $/ 24 \mathrm{~h}$ in Caco- 2 cells and more than 5-fold in HT-29 cells. In HT-29 cells, this increased level was significantly suppressed ( 4-fold) by pretreatment with a COX-2 inhibitor, celecoxib. Additionally, Araki et al (19) measured $\mathrm{PGE}_{2}$ production in the HT29-APC cell line, which contains a metallothionein promoter-driven, wild-type APC that is activated by zinc. When cells were cultured without zinc, $\mathrm{PGE}_{2}$ levels increased in a time-dependent manner to as high as $1400 \mathrm{pg} / \mathrm{ml}$ after $24 \mathrm{~h}$. Introduction of full-length APC expression (through zinc treatment) reduced $\mathrm{PGE}_{2}$ production by approximately 4-fold. Therefore, contrary to earlier studies, it appears that HT-29 cells express a metabolically active form of COX-2.

RNA interference is the most recent genetic tool that can target specific genes for post-transcriptional silencing. The implications for its use as a therapeutic agent are very promising. However, for the immediate future, identifying differentially expressed genes in response to COX-2 knockdown in colon cancer should assist in establishing the precise role of COX-2 in the mysteries of tumourigenesis.

\section{Acknowledgements}

The authors would like to thank Dr E.P. Diamandis (Mount Sinai Hospital, Toronto, Canada) and Dr S. Jothy (St. Michael's Hospital, Toronto, Canada) for their helpful discussions. B.B. is a recipient of Canadian Institutes of Health Research (CIHR) grants \#64225 and \#43950.

\section{References}

1. Smith WL and Dewitt DL: Prostaglandin endoperoxide $\mathrm{H}$ synthases-1 and -2. Adv Immunol 62: 167-215, 1996.
2. Williams CS, Mann M and DuBois RN: The role of cyclooxygenases in inflammation, cancer, and development. Oncogene 18: 7908-7916, 1999

3. Half E, Tang XM, Gwyn K, Sahin A, Wathen K and Sinicrope FA: Cyclooxygenase-2 expression in human breast cancers and adjacent ductal carcinoma in situ. Cancer Res 62: 1676-1681, 2002.

4. Kargman SL, O'Neill GP, Vickers PJ, Evans JF, Mancini JA and Jothy S: Expression of prostaglandin $\mathrm{G} / \mathrm{H}$ synthase- 1 and -2 protein in human colon cancer. Cancer Res 55: 2556-2559, 1995.

5. Molina MA, Sitja-Arnau M, Lemoine MG, Frazier ML and Sinicrope FA: Increased cyclooxygenase-2 expression in human pancreatic carcinomas and cell lines: growth inhibition by nonsteroidal anti-inflammatory drugs. Cancer Res 59: 4356-4362, 1999.

6. Ristimaki A, Sivula A, Lundin J, et al: Prognostic significance of elevated cyclooxygenase-2 expression in breast cancer. Cancer Res 62: 632-635, 2002.

7. Sano H, Kawahito Y, Wilder RL, et al: Expression of cyclooxygenase-1 and -2 in human colorectal cancer. Cancer Res 55: 3785-3789, 1995

8. Sinicrope FA, Lemoine M, Xi L, Lynch PM, Cleary KR, Shen Y and Frazier ML: Reduced expression of cyclooxygenase 2 proteins in hereditary nonpolyposis colorectal cancers relative to sporadic cancers. Gastroenterology 117: 350-358, 1999.

9. Soslow RA, Dannenberg AJ, Rush D, Woerner BM, Khan KN, Masferrer J and Koki AT: COX-2 is expressed in human pulmonary, colonic, and mammary tumors. Cancer 89: 2637-2645, 2000.

10. Tucker ON, Dannenberg AJ, Yang EK, et al: Cyclooxygenase-2 expression is up-regulated in human pancreatic cancer. Cancer Res 59: 987-990, 1999.

11. Van Rees BP, Saukkonen K, Ristimaki A, Polkowski W, Tytgat GN, Drillenburg P and Offerhaus GJ: Cyclooxygenase-2 expression during carcinogenesis in the human stomach. J Pathol 196: 171-179, 2002

12. Wolff H, Saukkonen K, Anttila S, Karjalainen A, Vainio H and Ristimaki A: Expression of cyclooxygenase-2 in human lung carcinoma. Cancer Res 58: 4997-5001, 1998.

13. Yamagata R, Shimoyama T, Fukuda S, Yoshimura T, Tanaka M and Munakata A: Cyclooxygenase-2 expression is increased in early intestinal-type gastric cancer and gastric mucosa with intestinal metaplasia. Eur J Gastroenterol Hepatol 14: 359-363, 2002.

14. Takahashi M, Mutoh M, Kawamori T, Sugimura T and Wakabayashi K: Altered expression of beta-catenin, inducible nitric oxide synthase and cyclooxygenase-2 in azoxymethaneinduced rat colon carcinogenesis. Carcinogenesis 21: 1319-1327, 2000.

15. Eberhart CE, Coffey RJ, Radhika A, Giardiello FM, Ferrenbach S and DuBois RN: Up-regulation of cyclooxygenase 2 gene expression in human colorectal adenomas and adenocarcinomas. Gastroenterology 107: 1183-1188, 1994.

16. Oshima M, Dinchuk JE, Kargman SL, et al: Suppression of intestinal polyposis in Apc delta716 knockout mice by inhibition of cyclooxygenase 2 (COX-2). Cell 87: 803-809, 1996.

17. Williams CS, Luongo C, Radhika A, et al: Elevated cyclooxygenase-2 levels in Min mouse adenomas. Gastroenterology 111: 1134-1140, 1996.

18. Hsi LC, Angerman-Stewart J and Eling TE: Introduction of fulllength APC modulates cyclooxygenase-2 expression in HT-29 human colorectal carcinoma cells at the translational level. Carcinogenesis 20: 2045-2049, 1999.

19. Araki Y, Okamura S, Hussain SP, et al: Regulation of cyclooxygenase- 2 expression by the Wnt and ras pathways. Cancer Res 63: 728-734, 2003.

20. Uematsu K, Kanazawa S, You L, et al: Wnt pathway activation in mesothelioma: evidence of Dishevelled overexpression and transcriptional activity of beta-catenin. Cancer Res 63: 4547-4551, 2003.

21. Cao Y, Pearman AT, Zimmerman GA, McIntyre TM and Prescott SM: Intracellular unesterified arachidonic acid signals apoptosis. Proc Natl Acad Sci USA 97: 11280-11285, 2000.

22. Dempke W, Rie C, Grothey A and Schmoll HJ: Cyclooxygenase-2: a novel target for cancer chemotherapy? J Cancer Res Clin Oncol 127: 411-417, 2001.

23. Rozic JG, Chakraborty C and Lala PK: Cyclooxygenase inhibitors retard murine mammary tumor progression by reducing tumor cell migration, invasiveness and angiogenesis. Int J Cancer 93: 497-506, 2001. 
24. Sheng H, Shao J, Morrow JD, Beauchamp RD and DuBois RN: Modulation of apoptosis and Bcl-2 expression by prostaglandin E2 in human colon cancer cells. Cancer Res 58: 362-366, 1998.

25. Backlund MG, Mann JR, Holla VR, et al: 15-Hydroxyprostaglandin dehydrogenase is down-regulated in colorectal cancer. J Biol Chem 280: 3217-3223, 2005.

26. Yan M, Rerko RM, Platzer P, et al: 15 -Hydroxyprostaglandin dehydrogenase, a COX-2 oncogene antagonist, is a TGF-betainduced suppressor of human gastrointestinal cancers. Proc Natl Acad Sci USA 101: 17468-17473, 2004.

27. Tai HH, Ensor CM, Tong M, Zhou H and Yan F: Prostaglandin catabolizing enzymes. Prostaglandins Other Lipid Mediat 6869: 483-493, 2002

28. Yoshimi N, Kawabata K, Hara A, Matsunaga K, Yamada Y and Mori H: Inhibitory effect of NS-398, a selective cyclooxygenase-2 inhibitor, on azoxymethane-induced aberrant crypt foci in colon carcinogenesis of F344 rats. Jpn J Cancer Res 88: 1044-1051, 1997.

29. Yoshimi N, Shimizu M, Matsunaga K, Yamada Y, Fujii K, Hara A and Mori H: Chemopreventive effect of N-(2-cyclohexyloxy-4-nitrophenyl)methane sulfonamide (NS-398), a selective cyclooxygenase-2 inhibitor, in rat colon carcinogenesis induced by azoxymethane. Jpn J Cancer Res 90: 406-412, 1999.

30. Giardiello FM, Hamilton SR, Krush AJ, et al: Treatment of colonic and rectal adenomas with sulindac in familial adenomatous polyposis. N Engl J Med 328: 1313-1316, 1993.

31. Steinbach G, Lynch PM, Phillips RK, et al: The effect of celecoxib, a cyclooxygenase- 2 inhibitor, in familial adenomatous polyposis. N Engl J Med 342: 1946-1952, 2000.

32. Maier TJ, Schilling K, Schmidt R, Geisslinger G and Grosch S: Cyclooxygenase-2 (COX-2)-dependent and -independent anticarcinogenic effects of celecoxib in human colon carcinoma cells. Biochem Pharmacol 67: 1469-1478, 2004.

33. Caplen NJ, Parrish S, Imani F, Fire A and Morgan RA: Specific inhibition of gene expression by small double-stranded RNAs in invertebrate and vertebrate systems. Proc Natl Acad Sci USA 98: 9742-9747, 2001

34. Elbashir SM, Harborth J, Lendeckel W, Yalcin A, Weber K and Tuschl T: Duplexes of 21-nucleotide RNAs mediate RNA interference in cultured mammalian cells. Nature 411: 494-498, 2001.

35. Fire A, Xu S, Montgomery MK, Kostas SA, Driver SE and Mello CC: Potent and specific genetic interference by doublestranded RNA in Caenorhabditis elegans. Nature 391: 806-811, 1998.
36. Denkert C, Furstenberg A, Daniel PT, et al: Induction of G0/G1 cell cycle arrest in ovarian carcinoma cells by the antiinflammatory drug NS-398, but not by COX-2-specific RNA interference. Oncogene 22: 8653-8661, 2003.

37. Sun Y, Tang XM, Half E, Kuo MT and Sinicrope FA: Cyclooxygenase- 2 overexpression reduces apoptotic susceptibility by inhibiting the cytochrome c-dependent apoptotic pathway in human colon cancer cells. Cancer Res 62: 6323-6328, 2002.

38. Ashkenazi A and Dixit VM: Apoptosis control by death and decoy receptors. Curr Opin Cell Biol 11: 255-260, 1999.

39. Green DR and Reed JC: Mitochondria and apoptosis. Science 281: 1309-1312, 1998.

40. Li P, Nijhawan D, Budihardjo I, Srinivasula SM, Ahmad M, Alnemri ES and Wang X: Cytochrome c and dATP-dependent formation of Apaf-1/caspase-9 complex initiates an apoptotic protease cascade. Cell 91: 479-489, 1997.

41. Wright JM: The double-edged sword of COX-2 selective NSAIDs. CMAJ 167: 1131-1137, 2002.

42. Shureiqi I, Chen D, Lotan R, Yang P, Newman RA, Fischer SM and Lippman SM: 15-Lipoxygenase-1 mediates nonsteroidal anti-inflammatory drug-induced apoptosis independently of cyclooxygenase-2 in colon cancer cells. Cancer Res 60: 6846-6850, 2000

43. Tsujii M and DuBois RN: Alterations in cellular adhesion and apoptosis in epithelial cells overexpressing prostaglandin endoperoxide synthase 2. Cell 83: 493-501, 1995.

44. Sun Y and Sinicrope FA: Selective inhibitors of MEK1/ERK44/42 and p38 mitogen-activated protein kinases potentiate apoptosis induction by sulindac sulfide in human colon carcinoma cells. Mol Cancer Ther 4: 51-59, 2005.

45. Ben-Av P, Crofford LJ, Wilder RL and Hla T: Induction of vascular endothelial growth factor expression in synovial fibroblasts by prostaglandin $\mathrm{E}$ and interleukin-1: a potential mechanism for inflammatory angiogenesis. FEBS Lett 372: 83-87, 1995.

46. Sheng H, Shao J, Washington MK and DuBois RN: Prostaglandin E2 increases growth and motility of colorectal carcinoma cells. J Biol Chem 276: 18075-18081, 2001.

47. Tsuji S, Kawano S, Tsujii M, Michida T, Masuda E, Gunawan ES and Hori M: [Mucosal microcirculation and angiogenesis in gastrointestinal tract]. Nippon Rinsho 56: 2247-2252, 1998.

48. Hsi LC, Baek SJ and Eling TE: Lack of cyclooxygenase-2 activity in HT-29 human colorectal carcinoma cells. Exp Cell Res 256: 563-570, 2000.

49. Kakiuchi Y, Tsuji S, Tsujii M, et al: Cyclooxygenase-2 activity altered the cell-surface carbohydrate antigens on colon cancer cells and enhanced liver metastasis. Cancer Res 62: 1567-1572, 2002 . 